\title{
Tooth Whitening Effect of Non-erosive Polymer based Hydrogen Peroxide Composition
}

\author{
Dohyuk Yoo, Jae-Hyun Ahn* \\ LG Science Park E10, Republic of Korea
}

\begin{abstract}
Objectives: In this study, the whitening efficacy and water resistance of polyvinyl acetate (PVAc), a non-erosive polymer, were investigated and compared with other tooth whitening hydrogen peroxide $\left(\mathrm{H}_{2} \mathrm{O}_{2}\right)$ compositions.

Methods: Oral applicable polymer solutions such as polyvinyl pyrrolidone (PVP) and polyvinyl acetate (PVAc) were prepared at a concentration of $15 \mathrm{wt} . \%$ in ethanol medium. $35 \%$ hydrogen peroxide solution was slowly added into prepared solutions in order to contain $2.8 \%$ hydrogen peroxide. Prepared PVP- $\mathrm{H}_{2} \mathrm{O}_{2}$ and $\mathrm{PVAc}-\mathrm{H}_{2} \mathrm{O}_{2}$ compositions were coated on slide glass. To evaluate water resistance, the coated samples were exposed $37^{\circ} \mathrm{C}$ water bath as similar to oral condition during one hour and 12 hours. Also, to confirm whitening effect (in-vitro), HAP discs were stained by Stookey-method. The oral applicable polymer compositions were treated on the stained HAP disc for one hour and 12 hours and then rinsed using ethyl alcohol and DI water. After each treatment the $L^{*}, a^{*}, b^{*}$ values were observed, then the overall color change $(\Delta E)$ was calculated compared to the initial measured values.
\end{abstract}

Results: $\mathrm{PVAc}-\mathrm{H}_{2} \mathrm{O}_{2}$ whitening composition as opposed to $\mathrm{PVP}-\mathrm{H}_{2} \mathrm{O}_{2}$ composition exhibited water resistance for 12 hours because of non-erosive feature of polyvinyl acetate. In the whitening estimation for one hour, all oral applicable polymer compositions which contain of $2.8 \%$ hydrogen peroxide exhibited similar results $(\mathrm{p} \geq 0.05)$. However, non-erosive tooth whitener as PVAc- $\mathrm{H}_{2} \mathrm{O}_{2}$ composition indicated more improved whitening effect than other tooth whitener composition such as $\mathrm{PVP}-\mathrm{H}_{2} \mathrm{O}_{2}$ under 12 hours whitening evaluation ( $\mathrm{p} \leq 0.05$ ). The $\triangle \mathrm{E}$ values of $\mathrm{PVP}-\mathrm{H}_{2} \mathrm{O}_{2}$ and $\mathrm{PVAc}-\mathrm{H}_{2} \mathrm{O}_{2}$ compositions were 3.461 and 3.585 under one hour. On the other hand, the $\triangle \mathrm{E}$ value of $\mathrm{PVAc}-\mathrm{H}_{2} \mathrm{O}_{2}$ composition as 7.204 was higher than that of $\mathrm{PVP}-\mathrm{H}_{2} \mathrm{O}_{2}$ composition as 4.632 under 12 hours.

Conclusions: Non-erosive polyvinyl acetate (PVAc) whitening composition showed a water resistance in similar oral condition and indicated an excellent tooth whitening effectiveness.

Keywords: tooth whitener, polyvinyl acetate, non-erosive, polyvinyl acetate, whitening effectiveness

Copyright (C) 2021. Korean Academy of Preventive Dentistry. All rights reserved.

This is an Open Access article distributed under the terms of the Creative Commons Attribution Non-Commercial License (http://creativecommons.org/licenses/ by-nc/4.0) which permits unrestricted non-commercial use, distribution, and reproduction in any medium, provided the original work is properly cited. 